ARTICLE

\title{
CD103+ ${ }^{+} \mathrm{CDC1}$ and endogenous CD8 ${ }^{+} \mathrm{T}$ cells are necessary for improved CD4OL-overexpressing CAR T cell antitumor function
}

Nicholas F. Kuhn ${ }^{1,2,3}$, Andrea V. Lopez ${ }^{2}$, Xinghuo Li ${ }^{2}$, Winson Cai ${ }^{2}$, Anthony F. Daniyan ${ }^{2}$ \& Renier J. Brentjens (1) $2 \bowtie$

While effective in specific settings, adoptive chimeric antigen receptor (CAR) T cell therapy for cancer requires further improvement and optimization. Our previous results show that CD4OL-overexpressing CAR T cells mobilize endogenous immune effectors, resulting in improved antitumor immunity. However, the cell populations required for this protective effect remain to be identified. Here we show, by analyzing Batf3 ${ }^{-/-}$mice lacking the $\mathrm{CD}^{-103^{+}}$ conventional dendritic cell type 1 ( $\mathrm{CDC1}$ ) subpopulation important for antigen cross-presentation, that CD4OL-overexpressing CAR T cells elicit an impaired antitumor response in the absence of $C D C 1 s$. We further find that CD4OL-overexpressing CAR T cells stimulate tumor-resident $\mathrm{CD}_{11 b^{-}} \mathrm{CD} 103^{-}$double-negative $(\mathrm{DN}) \mathrm{CDCs}$ to proliferate and differentiate into $C D C 1 s$ in wild-type mice. Finally, re-challenge experiments show that endogenous $\mathrm{CD}^{+}{ }^{+}$ $T$ cells are required for protective antitumor memory in this setting. Our findings thus demonstrate the stimulatory effect of CD4OL-overexpressing CAR T cells on innate and adaptive immune cells, and provide a rationale for using CD4OL-overexpressing CAR T cells to improve immunotherapy responses.

\footnotetext{
${ }^{1}$ Louis V. Gerstner Jr. Graduate School of Biomedical Sciences, Memorial Sloan Kettering Cancer Center, New York, NY, USA. ${ }^{2}$ Department of Medicine, Memorial Sloan Kettering Cancer Center, New York, NY, USA. ${ }^{3}$ Present address: Department of Pathology, University of California San Francisco, San

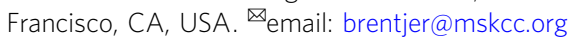


C himeric antigen receptors (CAR) are synthetic fusion proteins with an extracellular antigen-recognition domain and intracellular $\mathrm{T}$ cell stimulation domain, allowing $\mathrm{T}$ cell-mediated targeting of surface molecules on tumor cells independently of peptide-major histocompatibility complex (pMHC) presentation ${ }^{1}$. CD19-targeted CAR T cells have shown impressive results in patients with relapsed or refractory $\mathrm{B}$ cell malignancies, leading to the approval of anti-CD19 CAR T cell therapy in patients with diffuse large $B$ cell lymphoma and pediatric B-acute lymphocytic leukemia ${ }^{2,3}$. Whereas complete remission after anti-CD19 CAR T cell infusion can be reached in a large fraction of patients, a significant portion of responding patients relapses with CD19-negative disease and others do not respond at all ${ }^{2,4}$. This observation warrants improved $\mathrm{T}$ cellbased immunotherapies to target and eliminate malignant tumor cells.

Most $\mathrm{T}$ cell-based immunotherapies are focused on directly increasing the number of tumor-targeted $\mathrm{T}$ cells by adoptively transferring $\mathrm{T}$ cells into patients, removing immune-inhibitory checkpoints that act on the endogenous repertoire of the polyclonal $\mathrm{T}$ cell population, redirecting the endogenous $\mathrm{T}$ cell population to the tumor via bispecific antibodies, and/or genetically engineered $\mathrm{T}$ cells with CARs that allow supraphysiological antitumor $\mathrm{T}$ cell responses ${ }^{5}$. All these strategies directly manipulate and redirect immune responses on the T cell level. We have shown that CD40L-overexpressing CAR T cells have an increased antitumor effect, license antigen-presenting cells (APCs) in vivo, activate endogenous $T$ cells, and protect mice from CAR-antigen negative tumor challenge ${ }^{6}$. This strategy is an example of mobilizing immune effectors besides the adoptively transferred CAR $\mathrm{T}$ cells to eradicate tumor cells. However, the immune subpopulations necessary for relaying the information from CD40Loverexpressing CAR $\mathrm{T}$ cell to endogenous $\mathrm{T}$ cells and protecting mice from CAR-antigen negative tumor outgrowth remain to be determined.

Conventional DCs (cDCs), as opposed to plasmacytoid DCs, are the most potent APCs and can be further subdivided into cDC1 and $\mathrm{cDC} 2$ populations ${ }^{7}$. $\mathrm{cDC}$ s express high levels of MHCII and CD11c in both humans and mice. The transcription factors BATF3, IRF8, and ID2 are essential for cDC1 development, whereas $\mathrm{cDC} 2 \mathrm{~s}$ depend on the transcription factors RELB, IRF4, and $\mathrm{ZEB} 2{ }^{8}$. $\mathrm{CDC} 2 \mathrm{~s}$ are predominantly involved in initiating $\mathrm{CD} 4{ }^{+} \mathrm{T}$ cell responses against nematodes and viral infections ${ }^{9,10}$. So far, there is limited understanding of $\mathrm{CDC} 2$ function in the immune antitumor response, but a recent study has identified cDC2s in mice and humans and their involvement in $\mathrm{CD} 4^{+} \mathrm{T}$ cell activation $^{11}$.

cDC1s express surface CD8 $\alpha$ and CD103 (integrin $\alpha \mathrm{E}$ ) in lymphoid and non-lymphoid tissue, respectively. Both lymphoid and non-lymphoid tissue $\mathrm{cDC1}$ s share a very similar transcriptional profile and a central role in the adaptive immune response by cross-presenting antigen to cytotoxic $\mathrm{CD} 8{ }^{+} \mathrm{T}$ cells in antiviral and antitumor responses $7,12,13$. In humans, $\mathrm{cDC} 1$ s are identified by CD141/BDCA3 surface expression ${ }^{14}$ and seem to be excluded from tumor tissue compared to matched, healthy tissue ${ }^{15}$. Their role in tumor rejection is further supported by the finding that high levels of intratumoral $\mathrm{BDCA}^{+} \mathrm{cDCl}^{\mathrm{s}}$ correlate with responsiveness to anti-PD-1 immunotherapy in melanoma patients ${ }^{16}$. Thus, several preclinical tumor transplantation studies aimed at increasing the accumulation of tumor-resident $\mathrm{cDC} 1 \mathrm{~s}$ and noted that NK cell-derived fms like tyrosine kinase 3 ligand (FLT3L) and other $\mathrm{CDC} 1$ chemoattractants stimulated cDC1 recruitment to the tumor and controlled further tumor growth ${ }^{16,17}$. Importantly, the accumulation of tumor-resident cDC1s improved $\mathrm{CD}^{+} \mathrm{T}$ cell expansion and responses to antiPD-L1 treatment ${ }^{18}$
$\mathrm{T}$ cell-mediated antitumor responses are well characterized and can be based on recognition of non-mutated cancer-related antigens or neoantigens derived from mutated proteins ${ }^{19,20}$. The antigen is recognized by the TCR of the $\mathrm{CD}^{+}{ }^{+}$or $\mathrm{CD}^{+} \mathrm{T}$ cell on presented MHC-II or MHC-I, respectively. The importance of $\mathrm{CD}^{+} \mathrm{T}$ cellmediated tumor control through pMHC-I:TCR interactions is highlighted by the observation that MHC-I or $\beta 2 \mathrm{M}$ loss in tumor cells-both resulting in the absence of antigen presentation on the cancer cells surface-leads to tumor immune evasions and subsequent tumor outgrowth in patients ${ }^{21,22}$. Still, long-term survival for up to 10 years has now been described in patients with metastatic disease who were treated with $\mathrm{T}$ cell-mobilizing immunotherapies ${ }^{23}$. Similar results have been described for B-ALL patients treated with anti-CD19 CAR T cells in a long-term follow-up ${ }^{4}$.

However, many patients relapse with CAR-antigen-negative disease at later time points. Thus, a sustained antitumor response that is based on the highly cytotoxic effector function of the CAR $\mathrm{T}$ cell, plus the recruitment of cytotoxic non-CAR $\mathrm{T}$ cells recognizing tumor cell-specific antigens is explored in this study. We demonstrate that m1928z-CD40L CAR T cells can induce long-lived immune cell-based antitumor memory and, thereby, provide protection from CAR-antigen-negative tumor outgrowth in a preclinical setting.

\section{Results}

m1928z-CD40L CAR T cells upregulate CCR7 on tumorresident cDCs and skew the intratumoral DC population towards the $\mathrm{CD}_{11 b^{-}} \mathrm{CD}^{-}{ }^{-} \mathrm{DN}$ and $\mathrm{CD}^{-} 1 \mathrm{~b}^{-} \mathrm{CD}^{-}{ }^{+}{ }^{+} \mathrm{cDC1}$ phenotype. We have previously described in vivo licensing of APCs through CD40L-overexpressing CAR T cells in lymphoid tissue, but not in tumor tissue, which was most prominent 7 days after adoptive cell transfer $(\mathrm{ACT})^{6}$. This prompted us to analyze earlier time points after ACT by quantifying DC recruitment to both tumor and spleen (Fig. 1a). m1928z-CD40L CAR T cell treatment did not increase the recruitment of bulk MHC-II ${ }^{+} \mathrm{CD} 11 \mathrm{c}^{+} \mathrm{DCs}$ to the tumor tissue over time (Fig. 1b). Compared to m1928z CAR T cell treatment, CD40L-overexpressing CAR T cells induced the accumulation of splenic $\mathrm{MHC}-\mathrm{II}^{+} \mathrm{CD} 11 \mathrm{c}^{+}$DCs by day 7 after ACT (Fig. 1c). Besides the spleen, the secondary lymphoid organs are also comprised of lymph nodes where immune cell interactions are organized between members of the innate and adaptive immune

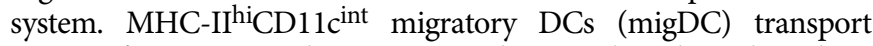
antigen from surrounding tissue to draining lymph nodes where they present antigen to circulating $\mathrm{T}$ cells for activation ${ }^{13,24,25}$. m1928z-CD40L CAR $\mathrm{T}$ cell treatment increased the migDC population in tumor-draining lymph nodes (tdLNs) (Fig. 1d). This increase in migDCs was instructed via CD40/CD40L interactions, as $C d 40^{-1-}$ mice lacked an increase in migDCs after $\mathrm{m} 1928 \mathrm{z}-$ CD40L CAR T cell treatment (Fig. 1d). By analyzing these different anatomical sites, we noticed that m1928z-CD40L CAR T cell treatment has no effect on DC tumor infiltration numbers-neither at earlier, nor later time points-nor does it affect the lymphoid compartment until one week after ACT.

Conventional DCs can be further divided into $\mathrm{CDC1}$ and cDC2 subpopulations. Both subpopulations have been described to have roles in antitumor immune responses, where they control $\mathrm{T}$ cell immunity ${ }^{18,26}$. Thus, we investigated DC subpopulations in m1928z-CD40L CAR T cell-treated mice. cDC1 and cDC2 populations can be immunophenotyped based on surface marker expression. Identified by high expression of the conventional DC markers MHC-II and CD11c, cDC1 populations in non-lymphoid tissue express the integrin $\mathrm{CD} 103$ and are $\mathrm{CD}_{11 b^{-}}$, whereas $\mathrm{CDC} 2 \mathrm{~s}$ are $\mathrm{CD} 11 \mathrm{~b}^{+} \mathrm{CD}_{103}-$ (Supplementary Fig. 1A). In the lymphoid tissue, the $\mathrm{CDC} 1$ population loses its CD103 expression and instead is identified by $\mathrm{CD} 8 \mathrm{a}$ expression, with $\mathrm{cDC} 2$ cells maintaining their 
a

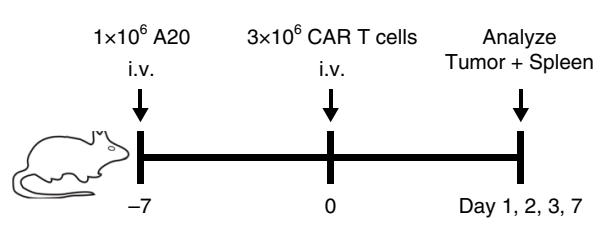

b

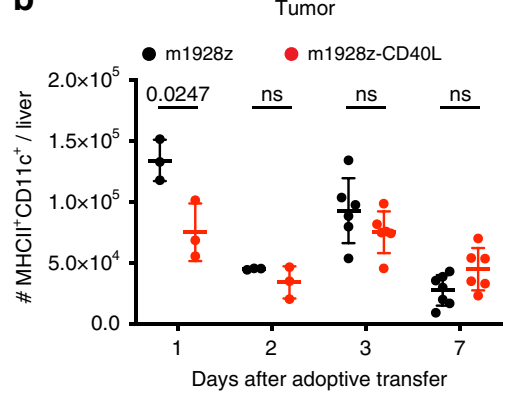

c

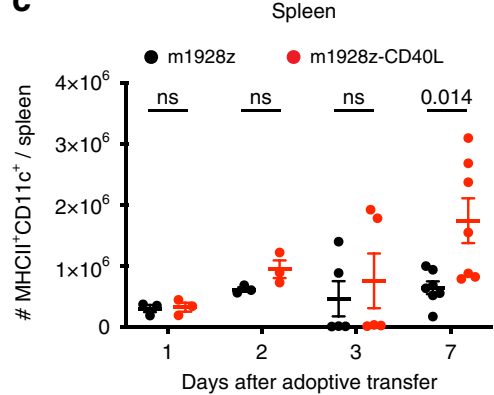

d

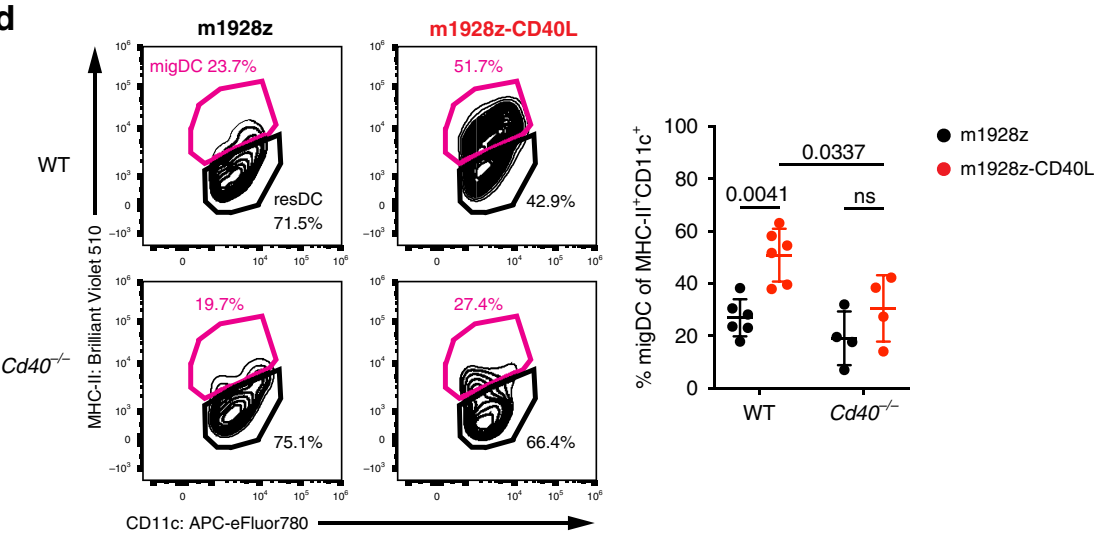

e
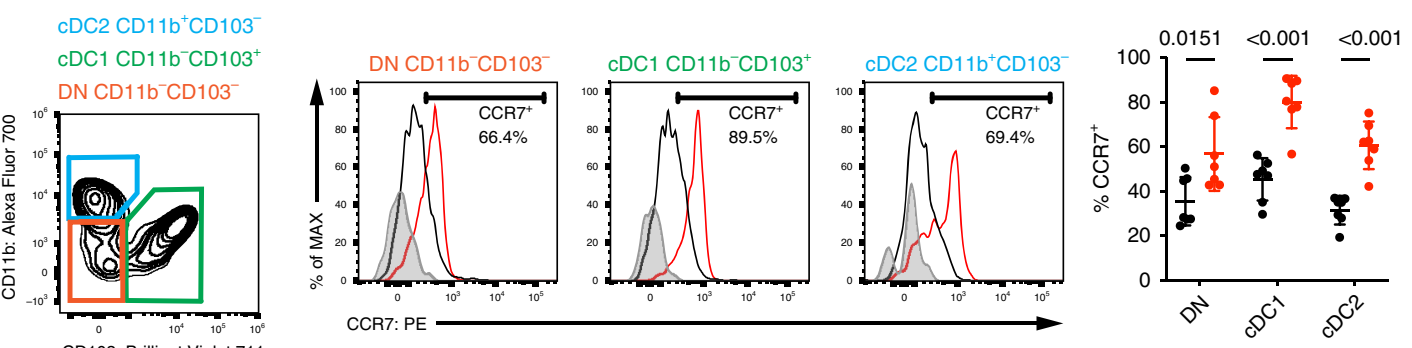

$\mathbf{f}$

Tumor
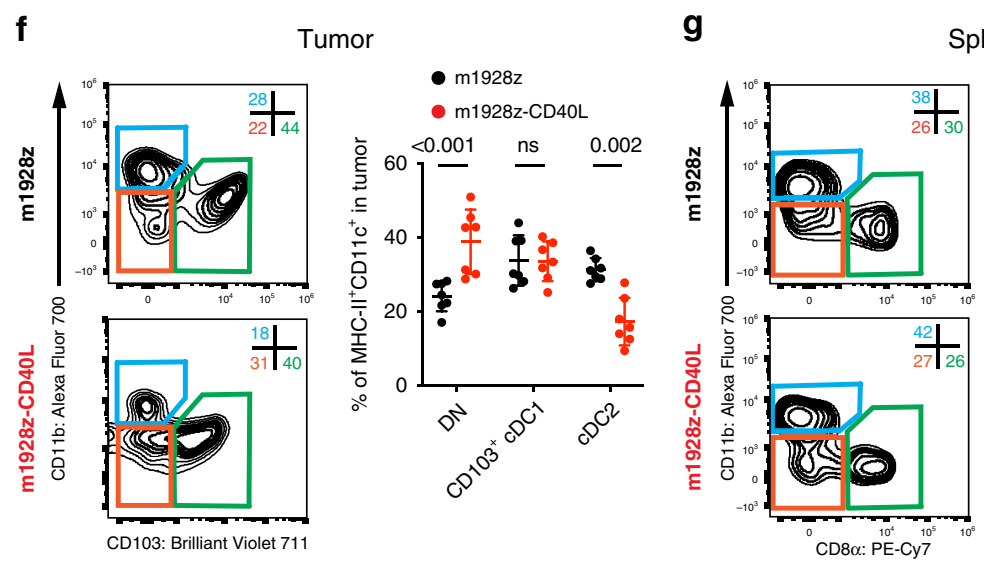

Spleen
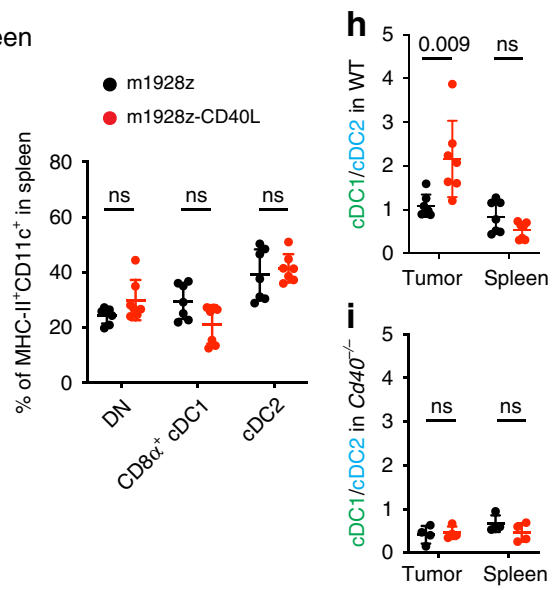

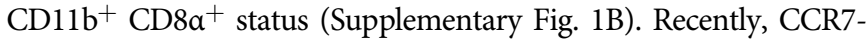
expressing $\mathrm{CD}_{103^{+}}{ }^{+}$DCs were identified as trafficking between tumor site and tdLN, transporting tumor antigen, and priming a $\mathrm{T}$ cell anti-tumor response ${ }^{25}$. The chemokine receptor CCR7 directs DC trafficking to $\mathrm{LNs}^{27}$ and we observed increased CCR7 expression on all three tumor-resident $\mathrm{MHC}-\mathrm{II}^{+} \mathrm{CD} 11 \mathrm{c}^{+} \mathrm{DC}$ populations after m1928z-CD40L CAR T cell treatment: $\mathrm{CD}_{11 b^{-}}$ $\mathrm{CD} 103^{-} \mathrm{DNs}, \mathrm{CD}_{11 b^{-}} \mathrm{CD} 103^{+} \mathrm{cDC} 1 \mathrm{~s}$, and $\mathrm{CD}^{-} 1 \mathrm{~b}^{+} \mathrm{CD} 103^{-}$ cDC2s (Fig. 1e). This suggested that m1928z-CD40L CAR T cell treatment recruits DCs to the spleen and tdLNs by inducing upregulation of CCR7 on tumor-resident DCs.

Besides upregulation of CCR7 surface-level expression, we wanted to investigate if m1928z-CD40L CAR $\mathrm{T}$ cell treatment affects the relative composition of the three intratumoral $\mathrm{CDC}$ subpopulations. CD40L-CAR T cell treatment increased the DN population, maintained the $\mathrm{CDC} 1$ population, resulting in a relative decrease in the $\mathrm{CDC} 2$ fraction (Fig. If and Supplementary Fig. 1C). These changes were not noticeable in the splenic and 
Fig. 1 m1928z-CD40L CAR T cells upregulate CCR7 on tumor-resident dendritic cells (DCs) and skew the intratumoral DC population towards the CD11b-CD103- double-negative (DN) and CD11b-CD103+ cDC1 phenotype. a Experimental layout for (b, c). b, c Absolute number of MHC-II ${ }^{+C D 11 C^{+}}$

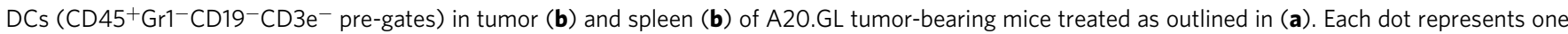
mouse (Day 1, 2: $n=3$ /group; Day 3: $n=6$ /group; Day 7: $n=6-7$ /group). Data are plotted as mean \pm SD. $p$-values were obtained from an unpaired twotailed Student's $t$ test. d A20.GL tumor-bearing wild-type (WT) or $\mathrm{Cd}_{40}-/-$ mice received $3 \times 10^{6} \mathrm{CAR}$ T cells intravenously (i.v.). The percentage of MHC-I/hiCD11 int migratory DCs (migDC) in tumor-draining lymph-nodes (tdLNs) was analyzed on day 7. Data are plotted as mean \pm SD and pooled from two independent experiments (WT: $n=6 /$ group; $C d 40^{-/-}: n=4$ /group). $p$-values were determined by two-way ANOVA test. e A20.GL tumor-bearing mice received $3 \times 10^{6}$ CAR T cells i.v. and CCR7 surface expression was analyzed on day 7 on CD11b-CD103- double-negative (DN) (orange), CD11b ${ }^{-} \mathrm{CD}_{103}{ }^{+} \mathrm{cDC1}$ (green), and CD11b+CD103+ $\mathrm{cDC2}$ (blue) populations in the tumor. Gray histogram, flow minus one. $\mathbf{f}$ A20.GL tumor-bearing mice received $3 \times 10^{6}$ CAR T cells i.v. and the percentage of CD11b-CD103- DN (orange), CD11b ${ }^{-}$CD103 ${ }^{+} \mathrm{cDC}^{-}$(green), and CD11b ${ }^{+} \mathrm{CD} 103^{+} \mathrm{cDC} 2$ (blue) $^{-}$ populations in the tumor was analyzed on day 7. $\mathrm{g} \mathrm{A20.GL} \mathrm{tumor-bearing} \mathrm{mice} \mathrm{received} 3 \times 10^{6} \mathrm{CAR}$ T cells i.v. and the percentage of CD11b ${ }^{-} \mathrm{CD} 8 \alpha^{-} \mathrm{DN}$ (orange), $\mathrm{CD}_{11 b} \mathrm{CD}^{-} \alpha^{+} \mathrm{cDC1}$ (green), and $\mathrm{CD} 11 \mathrm{~b}^{+} \mathrm{CD} 8 \alpha^{-} \mathrm{CDC2}$ (blue) populations in the spleen was analyzed on day 7. $\mathbf{h} \mathrm{The} \mathrm{cDC1} / \mathrm{cDC2}$ ratio in $\mathrm{A} 20$. GL tumor-bearing WT mice is plotted in the tumor and spleen of mice treated in $(\mathbf{f}, \mathbf{g})$. i The $\mathrm{CDC1} / \mathrm{CDC2}$ ratio in $\mathrm{A} 20 . \mathrm{GL}$ tumor-bearing $\mathrm{Cd} 40^{-} /-$mice is plotted on day 7 after receiving $3 \times 10^{6}$ CAR T cells. Data in (e-i) is plotted as mean \pm SD and pooled from two independent experiments. Each dot represents one mouse (e-h, $n=7$ /group; $\mathbf{i}, n=4$ /group). $p$-values were obtained from an unpaired two-tailed Student's $t$ test. ns, non-significant; i.v. intravenous; resDC, resident DC. Source data are provided as a Source Data file.

tdLN cDC populations (Fig. 1g and Supplementary Fig. 1D-F). These findings documented a change in the dendritic cell compartment of the tumor tissue after m1928z-CD40L CAR T cell treatment, wherein m1928z-CD40L CAR T cells skew the tumor-resident $\mathrm{CDC} 1 / \mathrm{cDC} 2$ ratio in favor of the $\mathrm{CDC} 1$ population (Fig. $1 \mathrm{~h}$ and Supplementary Fig. 1C). Lack of $\mathrm{cDC1} / \mathrm{cDC} 2$ ratio increase in $C d 40^{-/-}$mice showed that m1928z-CD40L CAR $\mathrm{T}$ cells mediate this effect in vivo via CD40/CD40L interactions (Fig. 1i). These observations highlighted the effect m1928zCD40L CAR T cells have on intratumoral DC subpopulations and prompted the question of its relevance in the antitumor response.

Improved antitumor response of $\mathbf{m 1 9 2 8 z - C D 4 0 L ~ C A R ~} \mathrm{T}$ cells requires presence of Batf3-expressing $\mathrm{CDC1}$. Next, we wanted to prevent $\mathrm{CDC} 1$ accumulation in the tumor and, thereby, assess its necessity in the m1928z-CD40L CAR T cell-mediated antitumor response. The transcription factor BATF3 is important for the development of $\mathrm{cDC1}$, as mice lacking Batf3 expression are deficient in $\mathrm{CD} 8 \mathrm{a}^{+} \mathrm{DCs}$ and tumor-resident $\mathrm{CD} 103^{+} \mathrm{DCs}$, making them more susceptible to $\mathrm{CD}^{+} \mathrm{T}$ cell-controlled viral infections and tumor growth ${ }^{12,26}$. We challenged both wild-type and Batf $3^{-/-}$mice with $\mathrm{GFP}^{+}$luciferase-expressing A20 lymphoma cells (A20.GL) and, as expected, no CD11b ${ }^{-} \mathrm{CD} 103^{+}$ cDC1 cells were present in the tumor of Batf $3^{-/-}$mice (Fig. $2 \mathrm{a}$ ). As we have previously reported $^{6}$, m1928z-CD40L CAR T cells increase survival of A20 tumor-bearing wild-type mice without the need for prior lymphodepletion (Fig. 2b). Subsequent treatment with CAR T cells showed that m1928z-CD40L CAR T cells in $B a t f 3^{-/-}$mice improves survival of tumor-bearing mice (Fig. $2 \mathrm{~b}$ ), demonstrating that the $\mathrm{CDC1}$ population is not solely responsible for in vivo $\mathrm{m} 1928 \mathrm{z}-\mathrm{CD} 40 \mathrm{~L}$ CAR $\mathrm{T}$ cell function. However, their presence in wild-type mice significantly improved survival and allowed complete tumor clearance by $\mathrm{m} 1928 \mathrm{z}$ CD40L CAR T cells in $40 \%$ of mice (Fig. 2b). Taken together, for m1928z-CD40L CAR T cells to exert their full antitumor response, the presence of $\mathrm{CDC1} 1 \mathrm{~s}$ is required.

The specific depletion of cDC2s remains challenging, because so far no marker has been identified that is exclusively expressed in $\mathrm{cDC} 2 \mathrm{~s}^{28}$. Use of CD11c-driven Cre recombinase expression to conditionally delete a $\mathrm{cDC} 2$ transcription factor is not restricted to the DC compartment, as CD11c is also expressed in macrophages and lymphoid cells ${ }^{29,30}$. This warrants further development of new mouse models that specifically deplete cDC2s, in order to gain a better understanding of their function in our system and other immune contexts.

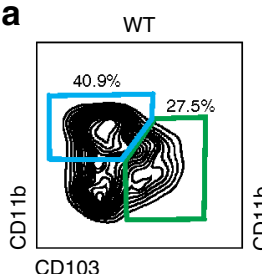

CD103

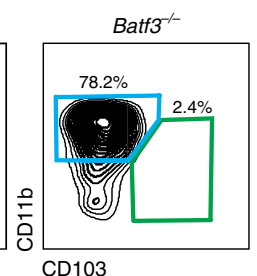

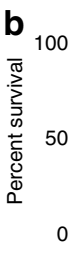

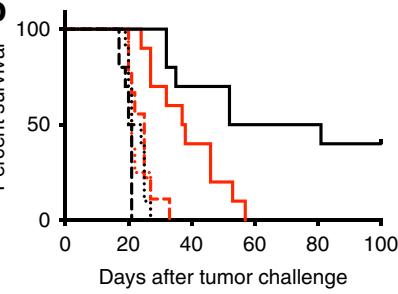

Fig. 2 Improved antitumor response of $m 1928 z-C D 40 L$ CAR T cells requires presence of Batf3-expressing CDC1. a Flow cytometry contour plots of the MHC-II+CD11c+ DC population in tumors of WT and Batf3-/mice on day 14 after A20.GL intravenous injection. Gates highlight CD11b + CD103- cDC2 (blue) and CD11b-CD103+ cDC1 (green) cells. Percentage of $\mathrm{CD}_{11} \mathrm{~b}^{-} \mathrm{CD}_{103}{ }^{+} \mathrm{cDC1s}$ in WT and Batf3-/- mice is plotted on the right. Data are plotted as mean \pm SD. Each dot represents one mouse (WT: $n=4$; Batf3 ${ }^{-}-, n=3$ ). $p$-value was determined using an unpaired two-tailed Student's $t$ test. b Survival of BALB/C WT or Batf3-/- mice challenged with $1 \times 10^{6}$ A20.GL cells and treated with $3 \times 10^{6}$ CAR T cells on day 7. $p$-values were determined by a two-tailed log-rank (Mantel-Cox) test. The summary of two independent experiments is plotted. Source data are provided as a Source Data file.

m1928z-CD40L CAR T cells stimulate tumor-resident CD11b $\mathrm{CD}{ }^{-} \mathrm{DN}$ cDCs to proliferate, up regulate IRF8, and differentiate to cDC1s. Next we wanted to investigate how the different CAR T cell treatments affect the cDC subpopulations as seen in Fig. 1. cDC1s consistently expressed the highest levels of the co-stimulatory molecule CD86 in all tissues analyzed (spleen, tumor, tdLN; Supplementary Fig. 2). m1928z-CD40L CAR T cell treatment did not further increase the high CD86 surface levels on $\mathrm{cDC1} 1 \mathrm{~s}$, whereas the lower CD86 expression on splenic DN and $\mathrm{CDC} 2$ cells was elevated following treatment (Supplementary Fig. 2B). This licensing of splenic cDCs matched the increase of splenic DC numbers seen in Fig. 1c, whereas tumor-resident cDCs remained unchanged (Fig. 1b and Supplementary Fig. 2C), 

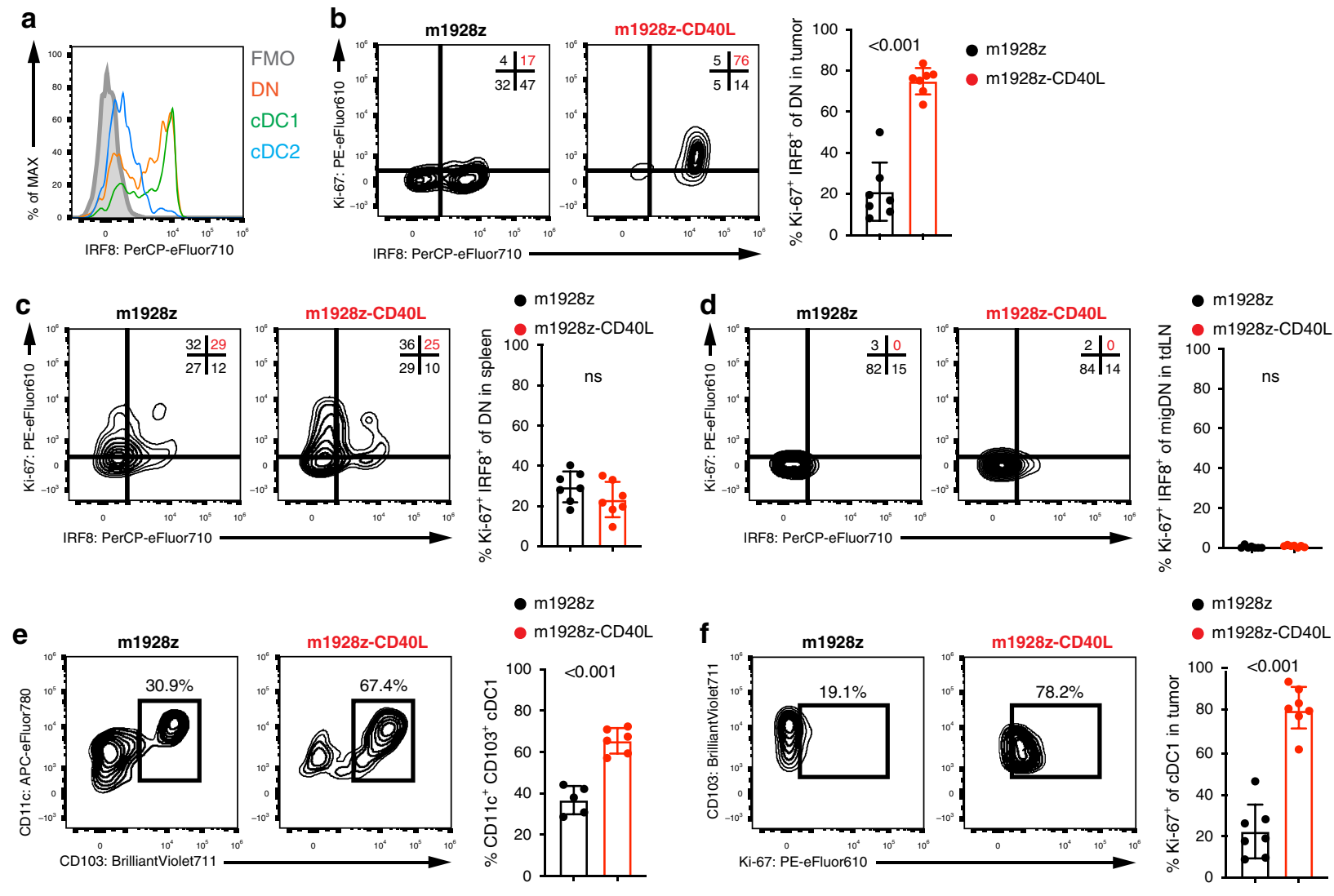

- m1928z-CD40L
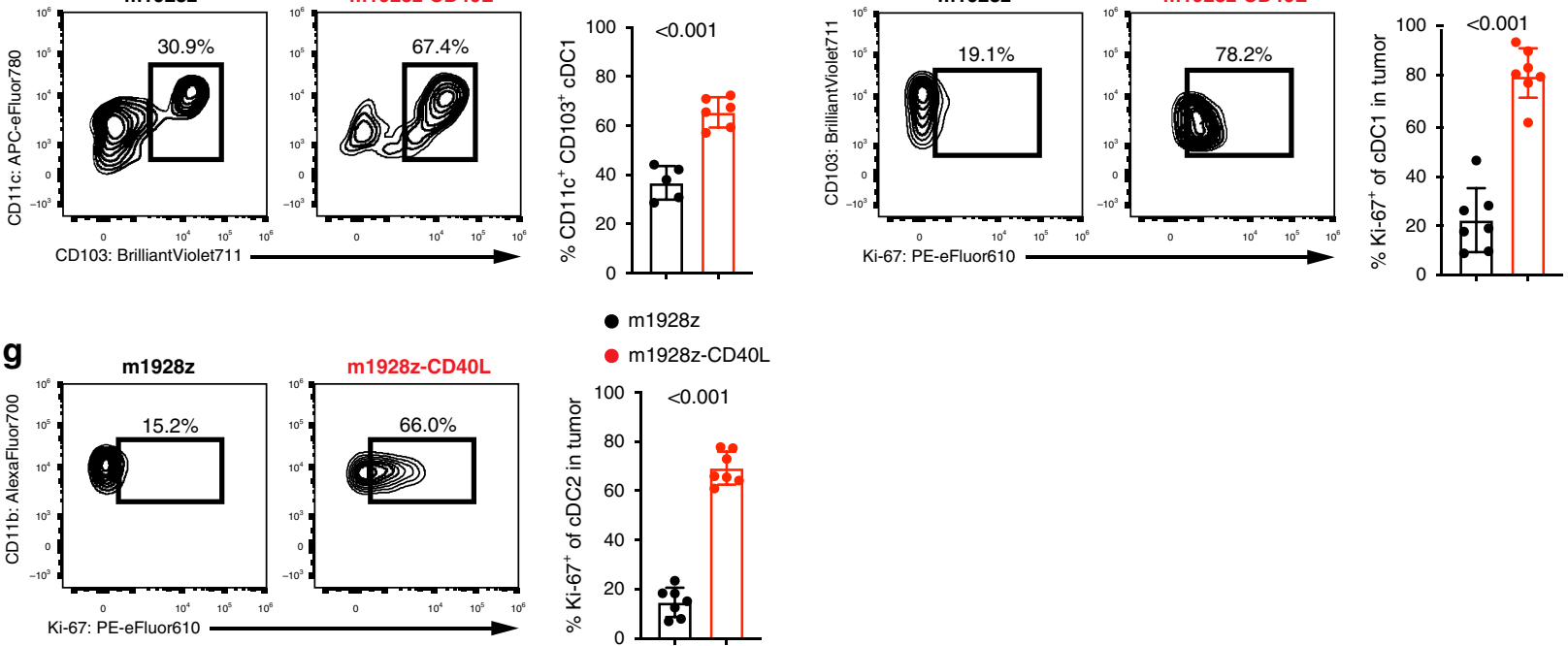

Fig. 3 m1928z-CD40L CAR T cells stimulate tumor-resident CD11b-CD103- DN cDCs to proliferate, upregulate IRF8, and differentiate to cDC1s. a IRF8

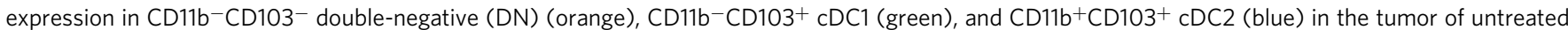
A20.GL tumor-bearing mice. FMO, flow minus one. b-d Ki-67 and IRF8 expression shown as flow cytometry contour plots in CD11b-CD103- DN cDCs in the tumor (b), spleen (c), and tumor-draining lymph nodes (tdLN) (d) of A20.GL tumor-bearing mice on day 7 after CAR T cell treatment. Percentage of $\mathrm{Ki}-67^{+}$IRF8 ${ }^{+} \mathrm{DN}$ cDCs is summarized from two independent experiments ( $n=7 /$ group). e CD45.2 ${ }^{+}$A20.GL tumor-bearing mice were treated with $3 \times$ $10^{6}$ CAR T cells i.v. and CD45.2+ CD11b-CD103- DN CDCs were isolated from the tumor on day 3 by FACS. Sorted CD45.2+ DN cells were cultured in vitro on a CD45.1 $1^{+}$bone-marrow stromal layer for 3 days and the percentage of CD11c ${ }^{+} \mathrm{CD} 103^{+} \mathrm{CDC1s}$ of all $\mathrm{CD} 45.2^{+}$cells was analyzed. Shown are representative contour plots and the quantification of the percentage of $\mathrm{CD11} \mathrm{c}^{+} \mathrm{CD} 103^{+} \mathrm{CDC1s}$. Each dot represents one in vitro culture. Data were

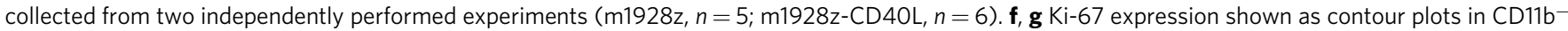
$\mathrm{CD} 103^{+}{ }^{\mathrm{cDC} 1 \mathrm{~s}}(\mathbf{f})$ and $\mathrm{CD} 11 \mathrm{~b}^{+} \mathrm{CD}_{103}{ }^{-} \mathrm{CDC2s}(\mathbf{g})$ in the tumor of A20.GL tumor-bearing mice on day 7 after CAR T cell treatment. Percentage of Ki-67 ${ }^{+}$ cells is summarized from two independent experiments ( $n=7 /$ group). Data in (b-g) is plotted as mean \pm SD. $p$-values were obtained from an unpaired two-tailed Student's $t$ test. ns, non-significant. Source data are provided as a Source Data file.

suggesting that cDCs respond differently to m1928z-CD40L CAR $\mathrm{T}$ cell treatment depending on their tissue site.

Focusing on the peripheral, differentiated CDC populations, we next assessed protein expression of the IRF8 transcription factor in tumor-derived $\mathrm{CDC}$ populations (Fig. 3a). In the periphery, IRF8 controls survival and function of terminally differentiated $\mathrm{cDC}^{3} \mathrm{~s}^{31,32}$. Furthermore, increased IRF8 expression in CD11 ${ }^{-}$ $\mathrm{CD}_{103^{-}}{ }^{-} \mathrm{DN}$ cells was shown to promote their differentiation into mature $\mathrm{CD}_{103}{ }^{+} \mathrm{cDC} 1 \mathrm{~s}^{18}$. Thus, we hypothesized that CD40LCAR $\mathrm{T}$ cell treatment skews the $\mathrm{cDC} 1 / \mathrm{cDC} 2$ ratio towards the cDC1 populations by stimulating the DN cells to expand, upregulate IRF8, and differentiate into cDC1s. We specifically noticed upregulation of IRF8 (readout of DN-to-cDC1 differentiation) and Ki-67 (readout for proliferation) in DN cells treated with CD40L-CAR T cell-treated mice (Fig. 3b). The increased expression of Ki-67 in the tumor-derived DN cells also correlated with the observed increase of the DN population in the tumor of CD40L-CAR T cell-treated mice (Fig. 1f), indicating that DN cells receive a proliferative signal upon CD40L-CAR T cell treatment. Intriguingly, splenic DN cells and DN cells from the tdLNs did not upregulate Ki-67 or IRF8 (Fig. 3c, d). Overall, tdLN cDCs did not present with a stimulated phenotype, as 
a
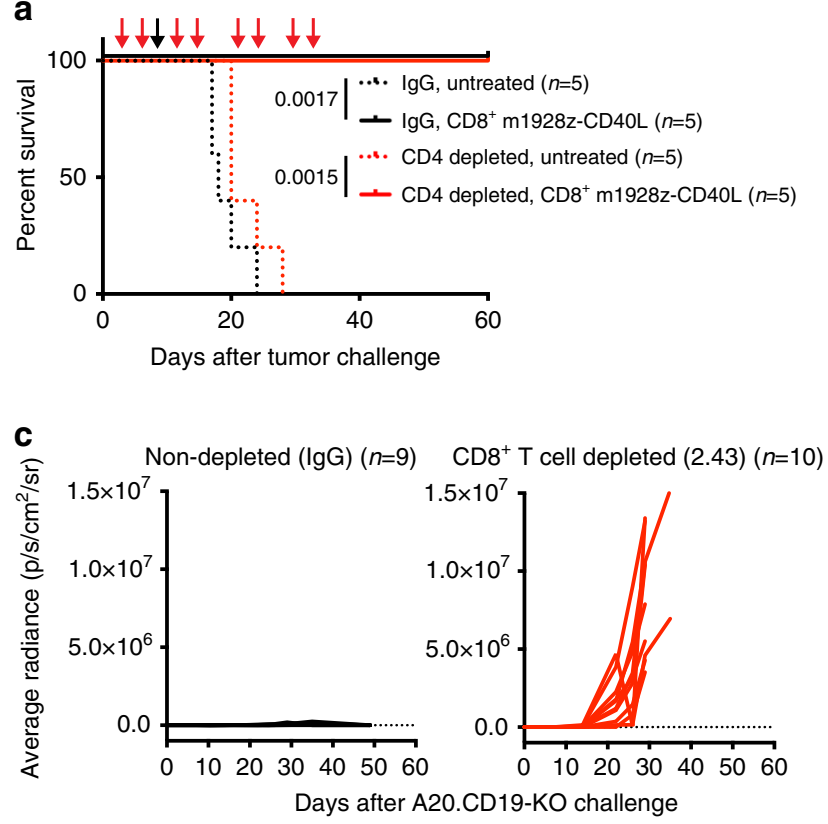

b

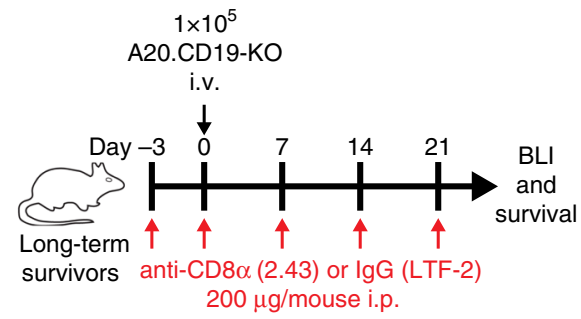

d
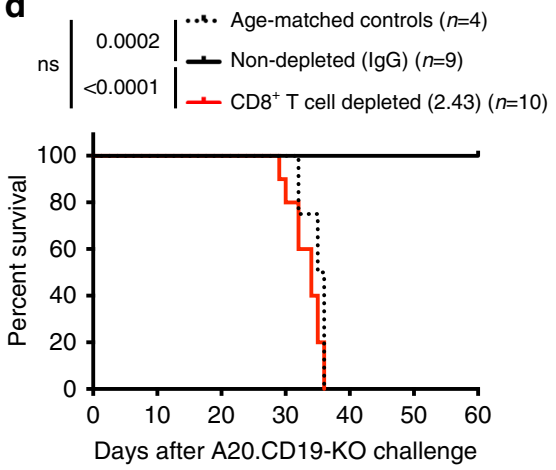

Fig. 4 CD8 $+\mathbf{T}$ cells are necessary for $\mathbf{m}$ 1928z-CD40L CAR $\mathbf{T}$ cell-mediated protection against antigen-negative tumor growth. a Survival of naive $\mathrm{BALB} / \mathrm{c}$ mice injected with $1 \times 10^{6} \mathrm{~A} 20 . \mathrm{GL}$ cells intravenously (i.v.) and either left untreated or treated with $3 \times 10^{6} \mathrm{CD} 8^{+} \mathrm{m} 1928 \mathrm{z}-\mathrm{CD} 40 \mathrm{~L} \mathrm{CAR} \mathrm{T}$ cells i.v. on day 7 (black arrow). For CD4 ${ }^{+} \mathrm{T}$ cell depletion, two cohorts of mice received $200 \mu \mathrm{g}$ of anti-CD4 depletion antibody (GK1.5) by intraperitoneal (i.p.) injection 2x per week for 3-4 weeks (red arrows). One of two representative experiments is shown. $\mathbf{b}$ Experimental scheme for (c, d). c Tumor burden of mice injected with luciferase-expressing CD19neg A20.CD19-KO cells was monitored using bioluminescence imaging. Average radiance per whole animal is plotted for the lgG treated mice $(n=9)$ and the CD8+ T cell-depleted mice $(n=10)$. d Survival of mice treated in $(\mathbf{b}, \mathbf{c})$. Naive age-matched BALB/c mice were used as controls. All $p$-values in figure were determined by a two-tailed log-rank (Mantel-Cox) test. ns, non-significant. Source data are provided as a Source Data file.

suggested by the lack of CD86 or Ki-67 upregulation (Supplementary Fig. 2D-G). This suggested a tumor-specific effect of cDC DN stimulation after m1928z-CD40L treatment.

Next, we wanted to assess if IRF8 upregulation in the DN population leads to DN-to-cDC1 differentiation. To address this, DN cells were isolated by fluorescence-activated cell sorting (FACS) from tumors of $\mathrm{m} 1928 \mathrm{z}$ and $\mathrm{m} 1928 \mathrm{z}-\mathrm{CD} 40 \mathrm{~L}$ CAR T celltreated mice and cultured ex vivo for 3 days to assess their potential to differentiate to $\mathrm{CDC} 1 \mathrm{~s}$ without any further stimuli. Both, DN cells from $\mathrm{m} 1928 \mathrm{z}$ and m1928z-CD40L CAR T celltreated mice differentiated into $\mathrm{cDC} 1 \mathrm{~s}$ ex vivo, albeit $\mathrm{DN}$ cells from $\mathrm{m} 1928 \mathrm{z}$-CD40L CAR T cell-treated mice differentiated into cDC1s at a significantly higher rate compared to m1928z CAR T cell-treated mice (Fig. 3e). Importantly, cDC1 and $\mathrm{cDC} 2$ cultured cells maintained their $\mathrm{CD}_{103}{ }^{+}$and $\mathrm{CD}_{103}^{-}$phenotype, respectively, regardless of prior stimulation (Supplementary Fig. 3A, B). Together, this implies that CD40L-CAR T cells affect the intratumoral $\mathrm{CDC} 1 / \mathrm{cDC} 2$ ratio by stimulating $\mathrm{CD} 1 \mathrm{~b}$ ${ }^{-} \mathrm{CD} 103^{-} \mathrm{DN}$ cell proliferation, upregulation of the $\mathrm{CDC1}$ skewing IRF8 transcription factor, and, consequently, differentiation of $\mathrm{DN}$ cDCs to $\mathrm{CDC} 1 \mathrm{~s}$ in the tumor tissue.

Besides DN-to-cDC1 differentiation, m1928z-CD40L CAR T cell treatment also promoted the proliferation of $\mathrm{CDC1s}$ and cDC2s, as suggested by Ki-67 staining (Fig. $3 f$, g). Curiously, the increased proliferation in all tumor-resident $\mathrm{CDC}$ subsets did not result in an increase in absolute cDC numbers after CD40L-CAR $\mathrm{T}$ cell treatment (Fig. 1b), suggesting that the proliferating tumorresident cDCs migrate out of the tissue to lymphoid structures, where they are present at higher numbers (Fig. 1c, e).

$\mathrm{CD8}^{+} \mathrm{T}$ cells are necessary for $\mathrm{m} 1928 \mathrm{z}-\mathrm{CD} 40 \mathrm{~L}$ CAR $\mathrm{T}$ cellmediated protection against antigen-negative tumor growth. With the increased priming of tumor-infiltrating $\mathrm{CAR}^{+}$and
$\mathrm{CAR}^{-} \mathrm{T}$ cells $^{6}$ and an impaired antitumor response in m1928z-CD40L CAR T cell-treated Batf3 $3^{-/-}$mice (Fig. 2d), we hypothesized that $\mathrm{m} 1928 \mathrm{z}-\mathrm{CD} 40 \mathrm{~L}$ CAR T cells prime the tumorinfiltrating $\mathrm{T}$ cell population through the $\mathrm{CDC1}$ population. Due to the known function of $\mathrm{cDC} 1$ cells cross-presenting antigen to $\mathrm{CD}^{+} \mathrm{T}$ cells, we focused on analyzing the CD8 ${ }^{+} \mathrm{T}$ cell compartment. As expected, after A20.GL tumor challenge and CAR T cell treatment, CAR ${ }^{\text {neg }} \mathrm{CD}^{+}{ }^{+} \mathrm{T}$ cells in $\mathrm{m} 1928 \mathrm{z}-\mathrm{CD} 40 \mathrm{~L}$ CAR $\mathrm{T}$ cell-treated mice produced more IFN $\gamma$ after ex vivo phorbol 12myristate 13-acetate (PMA)/ionomycin stimulation (Supplementary Fig. 4A, B). However, this elevated IFN $\gamma$ production was sustained in the absence of $\mathrm{CDC1}$ cells in Batf3 $3^{-/-}$mice (Supplementary Fig. 4A, B). This indicated that m1928z-CD40L CAR $\mathrm{T}$ cells provide a permissive environment in vivo that allows endogenous $\mathrm{CD}^{+}{ }^{+} \mathrm{T}$ cells to robustly produce IFN $\gamma$ independently of $\mathrm{cDC} 1$ cells.

To assess if the absence of cDC1 cells has any effect on the adoptively transferred $\mathrm{T}$ cell population, which might explain the impaired antitumor response in $B a t f 3^{-/-}$mice, IFN $\gamma$ production in $\mathrm{CD}^{+}{ }^{+} \mathrm{CAR}^{+} \mathrm{T}$ cells was assessed. Again, more IFN $\gamma$ was detected in m1928z-CD40L CAR T cells compared to $\mathrm{m} 1928 \mathrm{z}$ CAR $\mathrm{T}$ cells and this difference was not affected by genetic deletion of $\mathrm{cDC1}$ cells in Batf3 ${ }^{-/-}$mice (Supplementary Fig. 4C, D). This suggested that $\mathrm{CDC} 1$ cells are not responsible for the increased effector cytokine production observed in both $\mathrm{CAR}^{\text {neg }}$ and $\mathrm{CAR}^{+} \mathrm{T}$ cells of m1928z-CD40L CAR T cell-treated mice.

Assessment of cytokine production was done by ex vivo intracellular cytokine staining after non-specific activation of $\mathrm{T}$ cells by the diacylglycerol analog PMA and the calcium ionophore ionomycin. Together, these stimulants lead to protein kinase $\mathrm{C}$ activation (via PMA) and calcium release (via ionomycin) in T cells and activate $\mathrm{T}$ cells downstream of TCRinduced activation. Thus, analysis of PMA/ionomycin stimulated 
cell populations provides a readout for general cell activation potential, but not a readout for functional cell-specific tumor recognition.

Finally, we wanted to identify the cell population in the cured mice that mediate the protection against CAR-antigen-negative tumor outgrowth. To explore the possibility that endogenous $\mathrm{CD} 4{ }^{+} \mathrm{T}$ cells are necessary for the improved antitumor response of m1928z-CD40L CAR T cell treatment, we took advantage of the finding that $\mathrm{CD} 8{ }^{+} \mathrm{CAR} \mathrm{T}$ cells alone, but not $\mathrm{CD} 4{ }^{+} \mathrm{CAR}$ $\mathrm{T}$ cells, could cure A20.GL tumor-bearing mice (Supplementary Fig. 5A, B). This allowed isolated antibody-mediated depletion of $\mathrm{CD} 4{ }^{+} \mathrm{T}$ cells in the context of CD8 ${ }^{+}$m1928z-CD40L CAR $\mathrm{T}$ cell treatment, to assess the role of non-CAR $\mathrm{CD} 4^{+} \mathrm{T}$ cells in the antitumor response. CD4 ${ }^{+} \mathrm{T}$ cells were depleted with the antiCD4 antibody clone GK1.5 in A20.GL tumor-bearing mice before and after $\mathrm{CD}^{+}$m1928z-CD40L CAR T cell treatment (Fig. 4a). $\mathrm{CD}^{+} \mathrm{T}$ cell depletion was confirmed by flow cytometry in the peripheral blood of GK1.5-treated mice with a different anti-CD4 antibody clone (RM4-5) on the day of ACT (day 7) and a later time point (day 21) to make sure that no $\mathrm{CD} 4{ }^{+} \mathrm{T}$ cells are present that could potentially aid during the initial antitumor CAR T cell response (Supplementary Fig. 5C). Survival of CD4-depleted mice demonstrated that $\mathrm{CD}^{+}{ }^{+} \mathrm{T}$ cells are not necessary for the improved antitumor response through m1928z-CD40L CAR T cell treatment (Fig. 4a).

Focusing on the $\mathrm{CD}^{+} \mathrm{T}$ cell compartment, antibody-mediated depletion of $\mathrm{CD}^{+} \mathrm{T}$ cells before and/or after ACT would also lead to depletion of $\mathrm{CD}^{+} \mathrm{T}$ cells in the CAR $\mathrm{T}$ cell product, due to the long half-life of the depletion antibody and its systemic persistence. This would make it impossible to attribute the observed results to either the endogenous $\mathrm{CD} 8^{+} \mathrm{T}$ cell population or the adoptively transferred CAR T cells. To circumvent this problem, we decided to investigate the contribution of $\mathrm{CD}^{+}$ $\mathrm{T}$ cells to the memory response against CAR-antigen-negative tumor cell challenge. Long-term surviving mice that were initially cured from A20.GL tumor challenge by m1928z-CD40L CAR $\mathrm{T}$ cells were injected with CAR-antigen-negative A20.CD19-KO cells to exclude any CAR T cell-mediated antitumor response by persisting CAR T cells (Fig. 4b). Nineteen mice that were tumor free by bioluminescent imaging at day $50^{+}$after initial luciferaseexpressing A20.GL tumor challenge and m1928z-CD40L CAR T cell treatment were collected from three different previous experiments and separated into two cohorts (Supplementary Fig. 5D, E, F). Ten of 19 mice were $\mathrm{CD}^{+} \mathrm{T}$ cell-depleted by intraperitoneal injection with anti-CD8 antibody clone 2.43 (Fig. 4b). The remaining nine mice received the IgG control antibody. Complete $\mathrm{CD}^{+} \mathrm{T}$ cell depletion was confirmed (Supplementary Fig. 5G) and growth of luciferase-expressing A20.CD19-KO tumor cells were measured over time (Fig. 4c). Mice cured from primary A20.GL tumor challenge that were depleted of CD8 ${ }^{+} \mathrm{T}$ cells were not able to control A20.CD19-KO tumor outgrowth, unlike the IgG control mice (Fig. 4c). This resulted in a lack of survival due to disease progression (Fig. $4 \mathrm{~d}$ ). All relapsed mice died from outgrowth of $\mathrm{CD} 19^{-}$tumor cells, indicating that $\mathrm{CD}^{+} \mathrm{T}$ cell depletion did not cause reemergence of residual $\mathrm{CD}_{1} 9^{+}$tumor cells from the first tumor challenge (Supplementary Fig. 5H, I).

\section{Discussion}

This study describes the recruitment of tumor-specific endogenous $\mathrm{CD}^{+} \mathrm{T}$ cells after m1928z-CD40L CAR T cell treatment. Their mobilization was dependent on the presence of crosspresenting $\mathrm{cDC} 1 \mathrm{~s}$ and their elimination via anti-CD8 antibodymediated cell depletion made mice susceptible to CAR-antigennegative tumor cell outgrowth. These findings highlight the induction of a sustained host antitumor response by $\mathrm{m} 1928 \mathrm{z}-$ CD40L CAR T cells.

This effect is presumably mediated by the recognition of tumor-associated antigens (TAAs) presented on MHC-I by the cancer cells to the cytotoxic $\mathrm{CD} 8^{+} \mathrm{T}$ cells, as described in mice and human cancer patients 33,34 . The recognition of these TAAs by host $\mathrm{T}$ cells is especially important under the aspect of tumor heterogeneity and outgrowth of CAR-antigen-negative tumor cells after ACT, as seen in the clinic ${ }^{4}$. This early $\mathrm{CD}^{+} \mathrm{T}$ cell priming via CD40L-overexpressing CAR $\mathrm{T}$ cells seemed to generate a long-lived memory response that protected mice from CAR-antigen-negative tumor outgrowth. More careful analysis of TAA presentation on A20 tumor cells is required to assess the extent of immunodominant epitope recognition by the $\mathrm{CD}^{+} \mathrm{T}$ cell population. Exome sequencing of tumor cells in combination with in silico prediction of epitope presentation could identify such immunodominant epitopes and potential $\mathrm{CD}^{+} \mathrm{T}$ cell clones recognizing them ${ }^{35}$. This would inform the extent of $\mathrm{CD}^{+} \mathrm{T}$ cell tumor recognition and allow differentiation between a dominant clonal response and a possible oligoclonal $\mathrm{T}$ cell antitumor response.

Since A20 tumor cells are derived from transformed B cells, they express high levels of MHC-II, making them susceptible to $\mathrm{CD} 4^{+} \mathrm{T}$ cell-mediated recognition. However, the $\mathrm{CD}^{+}{ }^{+} \mathrm{T}$ cellspecific antitumor response did not seem to be relevant, as prior depletion of $\mathrm{CD}^{+}{ }^{+} \mathrm{T}$ cells did not lessen the m1928z-CD40L CAR $\mathrm{T}$ cell-mediated antitumor response. $\mathrm{CD} 4^{+} \mathrm{T}$ cells are important in helping to initiate a cytotoxic $\mathrm{CD}^{+} \mathrm{T}$ cell response through CD40 signaling on APCs via surface CD40L expres$\operatorname{sion}^{36}$. Overexpression of CD40L on CAR T cells-both on CD $4^{+}$ and $\mathrm{CD}^{+}{ }^{+} \mathrm{CAR} \mathrm{T}$ cells-obviates the need for $\mathrm{CD} 4^{+} \mathrm{T}$ cell help, similar to earlier studies demonstrating efficient $\mathrm{CD}^{+} \mathrm{T}$ cell priming with agonistic anti-CD40 antibodies independently of $\mathrm{CD}^{+} \mathrm{T}$ cell help ${ }^{37,38}$. Thus, $\mathrm{CD} 4^{+} \mathrm{T}$ cells are dispensable in mounting an efficient antitumor response, as long as CD40 signaling on APCs in provided by an alternative source, such as CD40L-overexpressing CAR T cells.

Cytokine production of endogenous $\mathrm{CD}^{+} \mathrm{T}$ cells was evident in Batf3 ${ }^{-/-}$mice, despite the absence of cross-presenting $\mathrm{CDC} 1 \mathrm{~s}$. Cross-priming of CD8 T cells independently of Batf3-expressing cDC1s has been described. $\mathrm{CD}_{169}{ }^{+}$macrophages have been identified as possible antigen cross-presenters for CD8 $\mathrm{T}$ cell stimulation in $\mathrm{LNs}^{39,40}$. In our system, we have previously reported the activation of both macrophages and $\mathrm{DCs}^{6}$, warranting further work to establish a potential stimulatory role of macrophages in CAR T cell-treated mice. Whereas we show that lack of Batf3-expressing cDC1s impairs the m1928z-CD40L CAR $\mathrm{T}$ cell antitumor response, identification and depletion of other cross-presenting cells could possibly completely ablate the antitumor response and provide evidence that other non-cDC1s are involved as well.

Why the $\mathrm{cDC} 1 / \mathrm{cDC} 2$ ratio increases in tumors of $\mathrm{m} 1928 \mathrm{z}$ CD40L CAR T cell-treated mice is unclear and warrants further investigation. The accumulation of $\mathrm{CDC} 1 \mathrm{~s}$ in the tumor tissue has been attributed to several NK cell-derived cytokines such as CCL5, FLT3L, and XCL1 16,17 . Conventional DCs in peripheral tissue have a half-life of about 3-6 days and are maintained by tissue-resident pre-cDCs that originate in and exit from the bone marrow ${ }^{41,42}$. This process can be observed in a mouse model of influenza infection, when pre-cDCs traffic to the infected lung tissue and locally increase the cDC numbers ${ }^{43}$. We see increased proliferation of CDCs after CD40L-CAR T cell treatment only in the tumor and not in lymphoid tissue. More importantly, CD40LCAR $T$ cell treatment skews the $\mathrm{cDC} 1 / \mathrm{cDC} 2$ ratio in favor of the cDC1s by promoting differentiation of progenitor $\mathrm{IRF}^{+} \mathrm{DN}$ progenitor cells to cDC1s. This is similar to published results, 
were homeostasis and generation of cDCs in peripheral tissue is maintained by mobilization of progenitor $\mathrm{cDCs}$ from the bone marrow $^{18,43}$. Both endogenous and exogenously applied FLT3L are instructive in mediating this effect ${ }^{18,41,42,44}$, suggesting a pathway that potentially is activated upon CD40L-CAR $\mathrm{T}$ cell treatment. It is unclear if pre-cDCs found in different tissues respond to differentiation signals differently, warranting further analysis of progenitor DCs residing in different tissues.

The priming of $\mathrm{CD}^{+} \mathrm{T}$ cells by $\mathrm{cDC} 1 \mathrm{~s}$ has been described to happen in the tdLNs after $\mathrm{CD}_{103}{ }^{+} \mathrm{cDC} 1 \mathrm{~s}$ take up the tumor antigen, upregulate CCR7 on their surface to home to the lymph node, where they then cross-present antigen to LN-resident $\mathrm{CD}^{+} \mathrm{T}$ cells $^{25}$. We noticed efficient priming of splenic CD8 ${ }^{+}$ $\mathrm{T}$ cells, indicating a more systemic, rather than local, $\mathrm{CD}^{+} \mathrm{T}$ cell activation by m1928z-CD40L CAR T cell treatment. This could potentially be explained by the accumulation of CAR $\mathrm{T}$ cells in the spleen, a site of high anti-CD19 CAR-antigen concentration. There, they induce licensing of $\mathrm{APCs}^{6}$ and provide a permissive environment for $\mathrm{T}$ cell priming. Our use of a disseminated lymphoma model has distinct characteristics compared to bona fide solid tumor models, with differences in stromal involvement and an immunosuppressive tumor microenvironment ${ }^{45,46}$. Use of a different tumor model, not targeting a ubiquitous antigen such as CD19 on B cells, could help to delineate if CD40L-modifed CAR T cells can prime $\mathrm{CD}^{+}{ }^{+} \mathrm{T}$ cells via APC licensing at a local level. However, m1928z-CD40L CAR T cell treatment did specifically lead to an increase in the tumor-resident $\mathrm{CD} 103^{+} \mathrm{cDC} 1$ population, whereas lymphoid $\mathrm{CD} 8 \alpha^{+} \mathrm{cDC} 1$ s were not elevated. This suggests priming of $\mathrm{CD}^{+} \mathrm{T}$ cells in the tumor microenvironment, which is possible and has been described for TILs in a previous study ${ }^{47}$. More detailed analysis of tumor-infiltrating versus tdLN-resident $\mathrm{CD}^{+}{ }^{+} \mathrm{T}$ cells after m1928z-CD40L CAR T cell treatment could help to delineate the logistics of cDC1-CD8 ${ }^{+}$ $\mathrm{T}$ cell interactions. In addition, it could inform us in which tissue environment the priming happens. This would help to design additional strategies improving this priming process, which is crucial for mounting a sustained, endogenous antitumor response.

\section{Methods \\ Animal models. All mice were bred and co-housed under SPF conditions in the animal facility of Memorial Sloan Kettering Cancer Center. All experiments were performed in ethical accordance with and upon approval by the MSKCC Institutional Animal Care and Use Committee (MSKCC protocol \#00-05-065). Wild-type BALB/c mice were purchased from Charles River. BALB/c CD45.1 (CByJ.SJL(B6)-Ptprc ${ }^{a} / \mathrm{J}$ ) were purchased from Jackson laboratories. BALB/c Cd40-/- (CNCr.129P2- $\left.C d 40^{t m I K i k} / \mathrm{J}\right)$ were kindly provided by Dr. Anna Valujskikh and bred in-house. $\mathrm{BALB} / \mathrm{c} \mathrm{Batf} 3^{-/-}\left(\mathrm{C} .129 \mathrm{~S}-\mathrm{Batf}^{\mathrm{tm} 1 \mathrm{Kmm}} / \mathrm{J}\right)$ were kindly provided by Dr. Barney Graham and bred in-house. 8-12-week old female mice were used in all experiments, unless indicated differently. Mice challenged with firefly luciferase-expressing tumor were imaged via bioluminescence to confirm equal tumor load and randomized to different treatment groups one day before treatment. Mice were euthanized via $\mathrm{CO}_{2}$ inhalation when tumor growth led to a weight gain of $20 \%$ due to a distended abdomen or when mice suffered from hind limb paralysis. The investigator was blinded when assessing the outcome.}

Cell lines. A20 cells (catalog number TIB-208) and Phoenix-ECO packaging cells (catalog number CRL-3214) were purchased from ATCC. All cell lines and culture experiments were maintained in RPMI-1640 supplemented with $10 \%$ heatinactivated FBS, nonessential amino acids, $1 \mathrm{mM}$ sodium pyruvate, $10 \mathrm{mM}$ HEPES, $2 \mathrm{mM}$ L-glutamine, $1 \%$ penicillin/streptomycin, $11 \mathrm{mM}$ glucose, and $2 \mu \mathrm{M} 2$ mercaptoethanol. Cell lines were routinely tested for potential mycoplasma contamination.

Generation of retroviral constructs. Plasmids encoding the CAR construct in the SFG $\gamma$-retroviral vector ${ }^{48}$ were used to transfect gpg29 fibroblasts (H29) with the ProFection Mammalian Transfection System (Promega) according to the manufacturer's instructions in order to generate vesicular stomatitis virus G-glycoproteinpseudotyped retroviral supernatants. These retroviral supernatants were used to construct stable Moloney murine leukemia virus-pseudotyped retroviral particleproducing Phoenix-ECO cell lines. The SFG-m1928z-CD40L vector was constructed by stepwise Gibson Assembly (New England BioLabs) using the cDNA of previously described anti-mouse CD19 scFv ${ }^{49}$, Myc-tag sequence (EQKLISEEDL), murine CD28 transmembrane and an intracellular domain, murine $\mathrm{CD} 3 \zeta$ intracellular domain without the stop codon, P2A self-cleaving peptide, and the murine CD40L protein.

Mouse $\mathbf{T}$ cell isolation and retroviral transduction. Mouse $\mathrm{T}$ cells were processed as described previously ${ }^{6}$. In brief, murine $\mathrm{T}$ cells were isolated from spleens of euthanized mice via negative selection using the EasySep Mouse T cell Isolation Kit (StemCell). Cells were then expanded in RPMI-1640 supplemented with 10\% heat-inactivated FBS, nonessential amino acids, $1 \mathrm{mM}$ sodium pyruvate, $10 \mathrm{mM}$ HEPES, $2 \mathrm{mM}$ L-glutamine, $1 \%$ penicillin/streptomycin, $11 \mathrm{mM}$ glucose, $2 \mu \mathrm{M}$ 2-mercaptoethanol, 100 IU of recombinant human IL-2 (rhIL-2) (Prometheus Therapeutics \& Diagnostics), and stimulated with anti-CD3/28 Dynabeads (Life Technologies) at a ratio of 1-to-2 (bead-to-cell). 24 and $48 \mathrm{~h}$ after bead stimulation, $\mathrm{T}$ cells were spinoculated on retronectin-coated plates with viral supernatant collected from Phoenix-ECO cells. After the second spinoculation, cells were rested for one day and then used in subsequent experiments.

Adoptive transfer of CAR T cells. For tumor studies, mice were inoculated i.v. with $1 \times 106$ firefly luciferase-expressing tumor cells on day 0 . On day 6, bioluminescence imaging using the Xenogen IVIS Imaging System (Xenogen) with Living Image software (Xenogen) for the acquisition of imaging datasets was done to guarantee equal tumor burden of mice at time of treatment. Mice were then randomized into different treatment cohorts and on day 7 , mice were treated with $1-3 \times 10^{6} \mathrm{CAR}^{+} \mathrm{T}$ cells intravenously. Tumor burden over time was monitored by bioluminescent imaging and quantified over the whole animal body as photons/ second $/ \mathrm{cm}^{2} /$ steradian $\left(\mathrm{p} / \mathrm{s} / \mathrm{cm}^{2} / \mathrm{sr}\right)$.

Tumor challenges with CAR-antigen-negative tumor cells. Long-term surviving $\mathrm{BALB} / \mathrm{c}$ mice $\left(50+\right.$ after initial tumor challenge with $\mathrm{CD} 19^{+}$tumor cells) were inoculated i.v. with $1 \times 10^{5}$ A20.CD19-KO cells (BALB/c). Naive age-matched mice served as controls. Survival was monitored over time.

Depletion of $\mathbf{C D 4}^{+}$or $\mathrm{CD8}^{+}$cell populations. To deplete $\mathrm{CD}^{+} \mathrm{T}$ cells in tumorbearing mice, $200 \mu \mathrm{g}$ of anti-CD4 depletion antibody (GK1.5) or IgG control antibody (LTF-2) were injected i.p. 2x per week for 4 weeks starting one week prior to CAR T cell treatment. To deplete $\mathrm{CD}^{+} \mathrm{T}$ cells in mice for re-challenge experiments with CD19-negative tumor cells, $200 \mu \mathrm{g}$ of anti-CD8 depletion antibody (2.43) or IgG control antibody (LTF-2) were injected i.p. on days -3, 0, 7, 14, and 21 relative to tumor cell challenge. Depletion of $\mathrm{CD}^{+}{ }^{+}$and $\mathrm{CD} 8^{+} \mathrm{T}$ cells was confirmed in the peripheral blood of treated mice by different antibody clones via flow cytometry (RM4-5 for CD4 and 53-6.7 for CD8 staining).

Cell isolation for subsequent analyses. Spleen and tumor tissue was processed as described previously ${ }^{6}$. Mice were euthanized via $\mathrm{CO} 2$ inhalation prior to organ removal. Harvested spleens were minced, filtered, washed in PBS, and red blood cells were lysed. Tumor tissue from the liver was mechanically disrupted, filtered, separated by Percoll density centrifugation, and red blood cells were lysed. Remaining cells were washed in PBS, counted, and used in subsequent analyses.

Flow cytometry and FACS sorting. Flow cytometric analyses were performed using a Beckman Coulter Gallios or a Thermo Fisher Attune NxT flow cytometer. Data were analyzed using FlowJo (Tree Star). DAPI $(0.5 \mathrm{mg} / \mathrm{ml}$, Sigma-Aldrich) or a LIVE/DEAD fixable violet dead cell stain kit (Thermo Fisher) were used to exclude dead cells in all experiments, and anti-CD16/CD32 antibody (93) was used to block non-specific binding of antibodies via Fc receptors. The following antimouse antibodies were used for flow cytometry: TruStain fcX (anti-mouse CD16/ 32) BioLegend Cat\# 101319, RRID:AB_1574973, $5 \mu \mathrm{g} / \mathrm{ml}$; anti-mouse CCR7 (clone 4B12) PE BioLegend, 120105, $2 \mu \mathrm{g} / \mathrm{ml}$; anti-mouse CD3 (clone 17A2) BrilliantViolet510 BioLegend 100233, RRID:AB_2561387, $1 \mu \mathrm{g} / \mathrm{ml}$; anti-mouse CD3ع (clone 145-2C11) PE-eFluor 610 eBioscience 61-0031, RRID:AB_2574514, $1 \mu \mathrm{g} / \mathrm{ml}$; anti-mouse CD4 (GK1.5) AlexaFluor 700 eBioscience 56-0041, RRID:AB_493999, $0.1 \mu \mathrm{g} / \mathrm{ml}$; anti-mouse CD8a (53-6.7) APC-eFluor 780 eBioscience 47-0081, RRID: AB_1272185, $0.1 \mu \mathrm{g} / \mathrm{ml}$; anti-mouse/human CD11b (M1/70) AlexaFluor 700 eBioscience 56-0112, RRID:AB_657585), $0.1 \mu \mathrm{g} / \mathrm{ml}$; anti-mouse CD11c (N418) APC-eFluor 780 eBioscience 47-0114, RRID:AB_1548663, $0.2 \mu \mathrm{g} / \mathrm{ml}$; anti-mouse CD19 (eBio1D3) APC-eFluor 780 eBioscience 47-0193, RRID:AB_10853189, $0.1 \mu \mathrm{g} / \mathrm{ml}$; anti-mouse CD19 (eBio1D3) PE eBioscience 12-0193, RRID:AB_657661, $0.1 \mu \mathrm{g} / \mathrm{ml}$; anti-mouse CD19 (eBio1D3) PE-eFluor 610 eBioscience 61-0193, RRID: AB_2574536, $0.5 \mu \mathrm{g} / \mathrm{ml}$; anti-mouse CD40 (1C10) PerCP-eFluor 710 eBioscience 46-0401, RRID:AB_2573677, $1 \mu \mathrm{g} / \mathrm{ml}$; anti-mouse CD40L (MR1) PE eBioscience 12-1541, RRID:AB_465887, $0.2 \mu \mathrm{g} / \mathrm{ml}$; anti-mouse CD45 (30-F11) BV605 BioLegend 103139, RRID:AB_2562341, $0.5 \mu \mathrm{g} / \mathrm{ml}$; anti-mouse CD45 (30-F11) PE-Cy7 eBioscience 25-0451, RRID:AB_469625, $0.5 \mu \mathrm{g} / \mathrm{ml}$; anti-mouse CD45.1 (A20) PEeFluor610 eBioscience 61-0453, RRID:AB_2574560, $0.2 \mu \mathrm{g} / \mathrm{ml}$; anti-mouse CD45.2 (104) PE-Cy7 eBioscience 25-0454, RRID:AB_2573350, $0.1 \mu \mathrm{g} / \mathrm{ml}$; anti-mouse CD103 (2E7) BV711 BioLegend 121435, RRID:AB_2686970, $1 \mu \mathrm{g} / \mathrm{ml}$; anti-mouse IFN $\gamma$ (XMG1.2) PE-Cy7 eBioscience 25-7311, RRID:AB_1257211,0.4 $\mu \mathrm{g} / \mathrm{ml}$; anti- 
moue IRF8 (V3GYWCH) PerCP-eFluor710 eBioscience 46-9852, $1.6 \mu \mathrm{g} / \mathrm{ml}$; antimouse Ki-67 (SolA15) PE-eFluor610 eBioscience 61-5698, $0.1 \mu \mathrm{g} / \mathrm{ml}$; anti-mouse Ly-6G/Ly-6C (Gr-1) (RB6-8C5) PE-eFluor 610 eBioscience 61-5931, RRID: AB_2574639, $0.2 \mu \mathrm{g} / \mathrm{ml}$; anti-mouse Ly-6G/Ly-6C (Gr-1) (RB6-8C5) PE-Cy7 eBioscience 25-5931, RRID:AB_469662, $0.2 \mu \mathrm{g} / \mathrm{ml}$; anti-mouse MHC class II (MHC-II) I-A/I-E (M5/114.15.2) BV510 BioLegend 107635, RRID:AB_2561397, $0.2 \mu \mathrm{g} / \mathrm{ml}$; anti-human Myc-tag (9B11) AlexaFluor 647 Cell Signaling $2233 \mathrm{~S}$, RRID:AB_10693328, 1:500. Quantification of total cell numbers by flow cytometry was done using 123count eBeads Counting Beads (Thermo Fisher). For intracellular staining of IFN $\gamma$, a single cell suspension of tumor or spleen tissue was generated and cells were stimulated with 1x Cell Stimulation Cocktail (PMA, ionomycin, brefeldin $\mathrm{A}$, and monensin) from Thermo Fisher for $5 \mathrm{~h}$. Cells were then processed with the Cytofix/Cytoperm Plus kit (BD Biosciences) per the manufacturer's instructions. For intracellular IRF8 staining, the eBioscience Foxp3/ Transcription Factor Staining Buffer Set (Thermo Fisher) was used according to the manufacturer's instructions. All antibodies were purchased from Biolegend, BD Biosciences, Cell Signaling, eBioscience, or Thermo Fisher. Sorting of splenocytes after tissue processing was done using a BD FACSAria under sterile conditions. Purity of cell populations was determined by reanalysis of an aliquot of sorted cell samples.

Ex vivo DC culture assay. Bone-marrow cultures were generated by seeding $1.2 \times$ $10^{6} / \mathrm{ml} \mathrm{CD} 45.1^{+}$BM cells into 24 -well plates $(500 \mu \mathrm{l} /$ well $)$ in complete RPMI media. Cells were supplemented with $100 \mathrm{ng} / \mathrm{ml}$ murine Flt3-Ligand (Peprotech) and $20 \mathrm{ng} / \mathrm{ml}$ murine GM-CSF (Peprotech). On day 2 of culture, $5-10 \times 10^{3}$ sorted $\mathrm{CD} 45.2^{+} \mathrm{CD} 11 \mathrm{~b}^{-} \mathrm{CD} 103^{-} \mathrm{DN}$ cDCs, CD $11 \mathrm{~b}^{-} \mathrm{CD} 103^{+} \mathrm{cDC} 1$, and $\mathrm{CD} 11 \mathrm{~b}^{+} \mathrm{CD} 103$ + cDC2 cells from CAR T cell-treated mice were separately added to the culture. After 3 days of co-culture, the percentage of DN cDCs, cDC1s, and cDC2s of all $\mathrm{CD} 45.2^{+}$cells was assessed by flow cytometry.

Quantification and statistical analysis. All statistical analyses were performed using GraphPad Prism software (GraphPad). Data points represent biological replicates and are shown as the mean \pm SEM or mean \pm SD as indicated in the figure legends. Statistical significance was determined using an unpaired two-tailed Student's $t$-test, unless otherwise noted. The log-rank (Mantel-Cox) test was used to determine statistical significance for overall survival in mouse survival experiments. Significance was assumed with ${ }^{*} p<0.05 ;{ }^{* *} p<0.01 ;{ }^{* * *} p<0.001$; ${ }^{* * * *} p<0.0001$.

Reporting summary. Further information on research design is available in the Nature Research Reporting Summary linked to this article.

\section{Data availability}

The authors declare that all data supporting the findings of this study are available within the paper and Supplementary Information. Source data are provided with this paper.

Received: 31 July 2019; Accepted: 23 October 2020;

Published online: 02 December 2020

\section{References}

1. Sadelain, M., Rivière, I. \& Riddell, S. Therapeutic T cell engineering. Nature 545, 423-431 (2017).

2. Maude, S. L. et al. Tisagenlecleucel in children and young adults with B-cell lymphoblastic leukemia. N. Engl. J. Med. 378, 439-448 (2018).

3. Neelapu, S. S. et al. Axicabtagene ciloleucel CAR T-cell therapy in refractory large B-cell lymphoma. N. Engl. J. Med. https://doi.org/10.1056/ NEJMoa1707447 (2017).

4. Park, J. H. et al. Long-term follow-up of CD19 CAR therapy in acute lymphoblastic leukemia. N. Engl. J. Med. 378, 449-459 (2018).

5. Dougan, M., Dranoff, G. \& Dougan, S. K. Cancer immunotherapy: beyond checkpoint blockade. Annu. Rev. Cancer Biol. https://doi.org/10.1146/ annurev-cancerbio-030518-055552 (2018).

6. Kuhn, N. F. et al. CD40 ligand-modified chimeric antigen receptor T cells enhance antitumor function by eliciting an endogenous antitumor response. Cancer Cell https://doi.org/10.1016/j.ccell.2019.02.006 (2019).

7. Merad, M., Sathe, P., Helft, J., Miller, J. \& Mortha, A. The dendritic cell lineage: ontogeny and function of dendritic cells and their subsets in the steady state and the inflamed setting. Annu. Rev. Immunol. 31, 563-604 (2013).

8. Murphy, T. L. et al. Transcriptional control of dendritic cell development. Annu. Rev. Immunol. https://doi.org/10.1146/annurev-immunol-032713120204 (2016).

9. Gao, Y. et al. Control of T helper 2 responses by transcription factor IRF4dependent dendritic cells. Immunity https://doi.org/10.1016/j. immuni.2013.08.028 (2013)
10. Krishnaswamy, J. K. et al. Migratory CD11b + conventional dendritic cells induce $\mathrm{T}$ follicular helper cell-dependent antibody responses. Sci. Immunol. https://doi.org/10.1126/sciimmunol.aam9169 (2017).

11. Binnewies, M. et al. Unleashing type-2 dendritic cells to drive protective antitumor CD4 + T cell immunity. Cell 177, 556-571.el6 (2019).

12. Hildner, K. et al. Batf3 deficiency reveals a critical role for CD8 $\alpha+$ dendritic cells in cytotoxic T cell immunity. Scienc https://doi.org/10.1126/ science.1164206 (2008).

13. Broz, M. L. et al. Dissecting the tumor myeloid compartment reveals rare activating antigen-presenting cells critical for $\mathrm{T}$ cell immunity. Cancer Cell https://doi.org/10.1016/j.ccell.2014.09.007 (2014).

14. Jongbloed, S. L. et al. Human CD141 + (BDCA-3) + dendritic cells (DCs) represent a unique myeloid DC subset that cross-presents necrotic cell antigens. J. Exp. Med. https://doi.org/10.1084/jem.20092140 (2010).

15. Lavin, Y. et al. Innate immune landscape in early lung adenocarcinoma by paired single-cell analyses. Cell https://doi.org/10.1016/j.cell.2017.04.014 (2017).

16. Barry, K. C. et al. A natural killer-dendritic cell axis defines checkpoint therapy-responsive tumor microenvironments. Nat. Med. https://doi.org/ 10.1038/s41591-018-0085-8 (2018).

17. Böttcher, J. P. et al. NK Cells stimulate recruitment of $\mathrm{cDCl}$ into the tumor microenvironment promoting cancer immune control. Cell https://doi.org/ 10.1016/j.cell.2018.01.004 (2018)

18. Salmon, H. et al. Expansion and activation of $\mathrm{CD} 103+$ dendritic cell progenitors at the tumor site enhances tumor responses to therapeutic PD-L1 and BRAF inhibition. Immunity 44, 924-938 (2016).

19. Rosenberg, S. A. \& Restifo, N. P. Adoptive cell transfer as personalized immunotherapy for human cancer. Science https://doi.org/10.1126/science. aaa4967 (2015).

20. Schumacher, T. N. \& Schreiber, R. D. Neoantigens in cancer immunotherapy. Science https://doi.org/10.1126/science.aaa4971 (2015).

21. Tran, E. et al. T-cell transfer therapy targeting mutant KRAS in cancer. $N$. Engl. J. Med. https://doi.org/10.1056/NEJMoa1609279 (2016).

22. Zaretsky, J. M. et al. Mutations associated with acquired resistance to PD-1 blockade in melanoma. N. Engl. J. Med. https://doi.org/10.1056/ NEJMoa1604958 (2016)

23. Postow, M. A., Sidlow, R. \& Hellmann, M. D. Immune-related adverse events associated with immune checkpoint blockade. N. Engl. J. Med. 378, 158-168 (2018).

24. Miller, J. C. et al. Deciphering the transcriptional network of the dendritic cell lineage. Nat. Immunol. https://doi.org/10.1038/ni.2370 (2012).

25. Roberts, E. W. et al. Critical role for CD103+/CD141+ dendritic cells bearing CCR7 for tumor antigen trafficking and priming of T cell immunity in melanoma. Cancer Cell https://doi.org/10.1016/j.ccell.2016.06.003 (2016).

26. Spranger, S., Dai, D., Horton, B. \& Gajewski, T. F. Tumor-residing Batf3 dendritic cells are required for effector $\mathrm{T}$ cell trafficking and adoptive $\mathrm{T}$ cell therapy. Cancer Cell https://doi.org/10.1016/j.ccell.2017.04.003 (2017).

27. Ohl, L. et al. CCR7 governs skin dendritic cell migration under inflammatory and steady-state conditions. Immunity https://doi.org/10.1016/j. immuni.2004.06.014 (2004).

28. Brown, C. C. et al. Transcriptional basis of mouse and human dendritic cell heterogeneity. Cell 179, 846-863.e24 (2019).

29. Van Rijt, L. S. et al. In vivo depletion of lung CD11c+ dendritic cells during allergen challenge abrogates the characteristic features of asthma. J. Exp. Med. https://doi.org/10.1084/jem.20042311 (2005).

30. Hebel, K. et al. Plasma cell differentiation in T-independent type 2 immune responses is independent of CD11chigh dendritic cells. Eur. J. Immunol. https://doi.org/10.1002/eji.200636356 (2006).

31. Sichien, D. et al. IRF8 transcription factor controls survival and function of terminally differentiated conventional and plasmacytoid dendritic cells, respectively. Immunity https://doi.org/10.1016/j.immuni.2016.08.013 (2016).

32. Ginhoux, F. et al. The origin and development of nonlymphoid tissue CD103+ DCs. J. Exp. Med. https://doi.org/10.1084/jem.20091756 (2009).

33. Matsushita, H. et al. Cancer exome analysis reveals a T-cell-dependent mechanism of cancer immunoediting. Nature https://doi.org/10.1038/ nature10755 (2012)

34. McGranahan, N. et al. Clonal neoantigens elicit $\mathrm{T}$ cell immunoreactivity and sensitivity to immune checkpoint blockade. Science https://doi.org/10.1126/ science.aaf1490 (2016).

35. Gubin, M. M. et al. Checkpoint blockade cancer immunotherapy targets tumour-specific mutant antigens. Nature 515, 577-581 (2014).

36. Behrens, G. et al. Helper T cells, dendritic cells and CTL immunity. Immunol. Cell Biol. https://doi.org/10.1111/j.1440-1711.2004.01211.x (2004).

37. Schoenberger, S. P., Toes, R. E. M., Van der Voort, E. I. H., Offringa, R. \& Melief, C. J. M. T-cell help for cytotoxic T-lymphocytes is mediated by CD40CD40L interactions. Nature 393, 480-483 (1998).

38. Bennett, S. R. M. et al. Help for cytotoxic-T-cell responses is mediated by CD40 signalling. Nature 393, 478-480 (1998). 
39. Bernhard, C. A., Ried, C., Kochanek, S. \& Brocker, T. CD169+ macrophages are sufficient for priming of CTLs with specificities left out by cross-priming dendritic cells. Proc. Natl Acad. Sci. USA. https://doi.org/10.1073/ pnas.1423356112 (2015).

40. Asano, K. et al. CD169-positive macrophages dominate antitumor immunity by crosspresenting dead cell-associated antigens. Immunity https://doi.org/ 10.1016/j.immuni.2010.12.011 (2011)

41. Liu, K. et al. In vivo analysis of dendritic cell development and homeostasis. Science https://doi.org/10.1126/science.1170540 (2009).

42. Hochweller, K. et al. Homeostasis of dendritic cells in lymphoid organs is controlled by regulation of their precursors via a feedback loop. Blood https:// doi.org/10.1182/blood-2008-11-188045 (2009).

43. Cabeza-Cabrerizo, M. et al. Tissue clonality of dendritic cell subsets and emergency DCpoiesis revealed by multicolor fate mapping of DC progenitors. Sci. Immunol. https://doi.org/10.1126/sciimmunol.aaw1941 (2019).

44. Lai, J. et al. Adoptive cellular therapy with $\mathrm{T}$ cells expressing the dendritic cell growth factor Flt3L drives epitope spreading and antitumor immunity. Nat. Immunol. https://doi.org/10.1038/s41590-020-0676-7 (2020).

45. Scott, D. W. \& Gascoyne, R. D. The tumour microenvironment in B cell lymphomas. Nat. Rev. Cancer https://doi.org/10.1038/nrc3774 (2014).

46. Binnewies, $\mathrm{M}$. et al. Understanding the tumor immune microenvironment (TIME) for effective therapy. Nat. Med. https://doi.org/10.1038/s41591-0180014-x (2018).

47. Thompson, E. D., Enriquez, H. L., Fu, Y.-X. \& Engelhard, V. H. Tumor masses support naive $\mathrm{T}$ cell infiltration, activation, and differentiation into effectors. $J$. Exp. Med. https://doi.org/10.1084/jem.20092454 (2010).

48. Riviere, I., Brose, K. \& Mulligan, R. C. Effects of retroviral vector design on expression of human adenosine deaminase in murine bone marrow transplant recipients engrafted with genetically modified cells. Proc. Natl. Acad. Sci. USA 92, 6733-6737 (1995).

49. Davila, M. L., Kloss, C. C., Gunset, G. \& Sadelain, M. CD19 CAR-targeted $\mathrm{T}$ cells induce long-term remission and $\mathrm{B}$ cell aplasia in an immunocompetent mouse model of B Cell acute lymphoblastic leukemia. PLoS ONE 8, e61338 (2013).

\section{Acknowledgements}

We thank the Flow Cytometry, Molecular Cytology core for technical assistance; the Center for Experimental Therapeutics at Memorial Sloan Kettering Cancer Center (MSKCC) for innovations in structures, functions and targets of mAb-based drugs for cancer; Drs. A. Schietinger and M. Sadelain for excellent critical comments; A. Rookard (MSKCC CMG) for assistance in mouse breeding; and all members of the Brentjens laboratory for critical comments and discussion. We want to acknowledge the following funding sources: this work was supported by a National Cancer Institute fellowship 5F31CA213668-02 (N.F.K.), National Institutes of Health grants R01CA138738-05, PO1CA059350, PO1CA190174-01, and P50CA192937-03 (R.J.B.); The Annual Terry Fox
Run for Cancer Research (New York, NY); Kate's Team; the Cabot Family Charitable Trust; the Leukemia and Lymphoma Society; the William Lawrence and Blanche Hughes Foundation; the Emerald Foundation (R.J.B.); and the institutional grant P30CACA008748 from the NIH.

\section{Author contributions}

Conceptualization, N.F.K. and R.J.B.; Investigation, N.F.K., A.V.L., X.L., W.C., and A.F. D.; Writing - Original Draft, N.F.K.; Writing - Review \& Editing, A.F.D. and R.J.B.; Supervision, R.J.B.; Funding Acquisition, N.F.K. and R.J.B.

\section{Competing interests}

R.J.B. receives royalties and grant support from Juno Therapeutics, is a consultant for Juno Therapeutics/Celgene and Gracell Therapeutics, Inc., and has submitted a patent related to this work. The authors have no additional financial interests.

\section{Additional information}

Supplementary information is available for this paper at https://doi.org/10.1038/s41467020-19833-3.

Correspondence and requests for materials should be addressed to R.J.B.

Peer review information Nature Communications thanks Maksim Mamonkin and the other, anonymous, reviewer(s) for their contribution to the peer review of this work. Peer reviewer reports are available.

Reprints and permission information is available at http://www.nature.com/reprints

Publisher's note Springer Nature remains neutral with regard to jurisdictional claims in published maps and institutional affiliations.

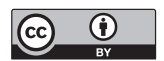

Open Access This article is licensed under a Creative Commons Attribution 4.0 International License, which permits use, sharing, adaptation, distribution and reproduction in any medium or format, as long as you give appropriate credit to the original author(s) and the source, provide a link to the Creative Commons license, and indicate if changes were made. The images or other third party material in this article are included in the article's Creative Commons license, unless indicated otherwise in a credit line to the material. If material is not included in the article's Creative Commons license and your intended use is not permitted by statutory regulation or exceeds the permitted use, you will need to obtain permission directly from the copyright holder. To view a copy of this license, visit http://creativecommons.org/ licenses/by/4.0/.

(c) The Author(s) 2020 